\title{
The role of ABC transporters' gene polymorphism in the etiology of intrahepatic cholestasis of pregnancy
}

\author{
Krzysztof Piątek' ${ }^{1}$, Grażyna Kurzawińska2, 3 , Justyna Magiełda², Krzysztof Drews ${ }^{2,}$, \\ Magdalena Barlik 2, 3, Zbyszko Malewski², Marcin Ożarowski ${ }^{4,5}$, Małgorzata Maciejewska' ${ }^{2,3}$, \\ Agnieszka Seremak-Mrozikiewicz'2,3
}

${ }^{1}$ Department of Gynecology and Obstetrics with Gynecological Oncology Subdivision, Regional Hospital in Zielona Góra, Poland

${ }^{2}$ Division of Perinatology and Women's Diseases, Poznan University of Medical Sciences, Poznan, Poland

${ }^{3}$ Laboratory of Molecular Biology, Division of Perinatology and Women's Diseases,

Poznan University of Medical Sciences, Poznan, Poland

${ }^{4}$ Department of Pharmacology and Phytochemistry, Institute of Natural Fibers and Medicinal Plants, Poznan, Poland

${ }^{5}$ Department of Pharmaceutical Botany and Plant Biotechnology, Poznan University of Medical Sciences, Poznan, Poland

\begin{abstract}
Objectives: The etiology of intrahepatic cholestasis of pregnancy (ICP) involves environmental, hormonal and genetic factors. It is thought that ICP may be related to the polymorphic variants of several genes involved in the metabolism and transport of bile acids (BA). The goal of our study was to evaluate the possible role of genetic polymorphic variants of $A B C$ transporters in patients with ICP.

Material and methods: 96 women with ICP (mean age of 30.42 years, mean gestational age of 36.83 gestation weeks) and 211 healthy pregnant women (mean age of 30.68 years, mean gestational age of 39.05 gestation weeks) were enrolled in the study. Genetic analysis was performed using a polymerase chain reaction / restriction fragment length polymorphism (PCR/RFLP) method. The following polymorphisms were analysed: 1331T > C (V444A) ABCB11 and 1954A > G (R652G) ABCB4

Results: Our analysis of frequency of genotypes and alleles of the 1954A > G ABCB4 polymorphism revealed no significant differences between the ICP and control groups. For the 1331T > C polymorphism of the ABCB11 gene the results revealed a higher frequency of $1331 \mathrm{CC}$ genotypes in the ICP group (39.58\% vs. $29.38 \%$. OR $=1.57, \mathrm{p}=0.05)$. Also, the frequency of the $1331 \mathrm{C}$ allele was higher in the ICP group compared to the control group $(64.06 \%$ vs. $55.69 \%, \mathrm{OR}=1.42, \mathrm{p}=0.03)$.

Conclusions: The overrepresentation of mutated variants of the 1331T > C ABCB11 polymorphism in the ICP group suggests its contribution to the etiology of the intrahepatic cholestasis of pregnancy. Analysis of genotypes' co-existence pointed to the possibility of the mutated variants of polymorphism 1954A > G ABCB4 and 1331T > C ABCB11 having a summation effect on the development of ICP.
\end{abstract}

Key words: intrahepatic cholestasis of pregnancy, ICP, bile acid, ABC transporter, polymorphism

Ginekologia Polska 2018; 89, 7: 393-397

\section{INTRODUCTION}

Intrahepatic cholestasis of pregnancy (ICP) is an obstetrical complication, which affects about $1.5 \%$ of pregnancies among Caucasians. The condition is quite serious since it may lead to intrauterine fetal demise. The relevant process behind ICP is the excessive accumulation of bile acids in hepatocytes and the inhibition of bile excretion [1]. Overproduction of bile acids or their impaired removal from hepatocytes may be the reason of this pathology, which leads to increased bile acid serum concentration [2-4].
Some of the studies show that polymorphic variants of genes encoding $A B C$ transporting proteins may play a role in the etiology of ICP. An ABCB11 gene encodes an $A B C$ transporter named Bile Salt Export Pump (BSEP) that is responsible for the removal of bile acids from hepatocytes [5]. The degree of the impairment of bile acid transport by BSEP depends on the polymorphic variants of $A B C B 11$ gene. The gene is localized on chromosome 2, region q31.1 and consists of 28 exons. According to the literature, the most frequent Caucasian-specific single nucleotide polymorphism 
in the $A B C B 11$ gene is 1331T > C (rs2287622). The transition of thymine into cytosine translates into alanine in place of valine at the position 444 of the protein sequence $[6,7]$.

Another potent phospholipid transporter is involved in bile shuttling, namely a Multidrug Resistance Protein 3 (MDR3). The MDR3 protein is encoded by ABCB4 gene $[8,9]$. It is found on chromosome 7, position 7q21.12 [10,11]. One of the most frequently analyzed $A B C B 4$ gene polymorphism is $1954 A>G$ in exon 16 ( $r$ 2230028). The result of transition of adenine into guanine results in substitution of arginine with glycine at the position 652 of protein sequence (R652G, Arg652Gly).

Both BSEP and MRD3 are a part of MDR/TAP protein family composed of ATP-active membrane transporters ABC. $A B C$ proteins transport many different molecules through the cellular membrane and a reduction of its expression may lead to excessive accumulation of toxic metabolites within cells [12-14].

There are some observations suggesting that hereditary impairment of $A B C B 4$ and $A B C B 11$ gene products due to gene polymorphism may be a reason of hepatic cirrhosis in early childhood $[15,16]$. Thus, the dysfunctional $A B C B 4$ and $A B C B 11$ genes may also be responsible for the development of ICP.

The aim of the study was to explore the possible role of gene variants encoding $A B C B$-type transporters in the etiology of ICP. The frequency of single nucleotide polymorphism was analyzed in two genes that encode the export pumps of bile acid salts: ABCB 11 (BESEP) (1331T > C, V444A polymorphism) and ABCB4 (MDR3) (1954A > G, R652G polymorphism).

\section{MATERIAL AND METHODS}

A total of 96 women with ICP diagnosed in the second half of pregnancy (mean age $30.42 \pm 4.38$ years, mean gestational age $36.83 \pm 2.75 \mathrm{gw}$.) and 211 healthy pregnant women (mean age $30.68 \pm 4.67$ years, mean gestational age $39.05 \pm 1.22 \mathrm{gw}$.) were enrolled into the study. The analysis was performed at the Division of Perinatology and Women's Diseases of Poznan University of Medical Sciences in Poznan and at the Department of Gynecology and Obstetrics with Gynecological Oncology Subdivision of Regional Hospital in Zielona Góra in the years 2013-2017 (Poznan University of Medical Sciences Bioethics Committee permission no 842/13). All subjects were informed about the goal of the study and gave their written consent.

The ICP was diagnosed on the basis of clinical and biochemical criteria such as: typical itching without rush, fasting total bile acids (TBA) serum concentration higher than $10 \mu \mathrm{mol} / \mathrm{L}$, increased concentration of aminotransferase (ALT, AST), symptoms subside within 2-3 weeks after delivery. The exclusion criteria were as follows: infection with hepatitis virus type $A, B$ or $C$, autoimmune diseases,

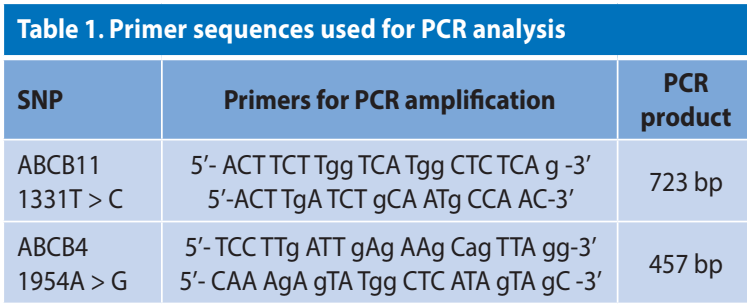

excessive alcohol drinking, HIV infection and all kinds of hepatic impairments and dermatological diseases that are connected with itching. All women were Caucasian race, Polish origin with singleton pregnancy.

The following records were taken of all the patients from both groups (ICP and control group): detailed obstetrical history, age, gestational age at the delivery, height, weight prior to and at the end of pregnancy, systolic and diastolic blood pressure, mode of delivery and the newborn condition. All lab tests were performed at the Central Laboratory of Gynecological-Obstetrical Hospital of Poznan University of Medical Sciences.

Genomic DNA was extracted using QIAamp DNA Blood Mini Kit (Qiagen, Germany) according to the manufacturer's recommendations. Genotyping was performed at the Laboratory of Molecular Biology of Poznan University of Medical Sciences using polymerase chain reaction and restriction fragment length polymorphism (PCR/RFLP) method with primers published by Dias [17] and Bronsky et al. [18] (Tab. 1). The obtained DNA fragments were hydrolyzed with the following restriction enzymes: BsuRI for $A B C B 11$ and TspRI for ABCB4.

The observed results and clinical data of patients and newborns were analyzed statistically with $\mathrm{R}$ software (version 3.4.2, http://cran.r-project.org) and $p<0.05$ was considered statistically significant.

\section{RESULTS}

\section{Analysis of clinical and laboratory data}

The analysis of both ICP and control groups has revealed some statistically significant differences in the duration of pregnancy ( $36.83 \pm 2.75 \mathrm{gw}$. in ICP group vs. $39.05 \pm 1.22 \mathrm{gw}$. in controls, $\mathrm{p}<0.0001)$. Weight gain throughout pregnancy was lower in the ICP group compared to controls $(4.21 \pm 1.98$ vs. $5.42 \pm 1.74, p<0.0001)$. Also, the ICP group had a statistically significant $(p<0.0001)$ lower body mass of newborns and a slightly lower 5 th minute Apgar score compared to the controls $(3083.00 \pm 634.95 \mathrm{~g}$ vs. $3425.00 \pm 433.82$ and $9.74 \pm 0.75$ vs. $9.97 \pm 0.23$ respectively). The interesting observation made was a lower placental mass in the ICP group compared to the controls $(579.11 \pm 150.93 \mathrm{~g}$ vs. $620.18 \pm 111.37 \mathrm{~g}, \mathrm{p}=0.02)$. The other values: first minute Apgar score or arterial and venous $\mathrm{pH}$ values were not statistically different between the groups. 


\section{Analysis of 1331T > C ABCB11 and 1954A > G ABCB4 polymorphism}

The genetic comparison of the ICP and the control group regarding the $1331 \mathrm{~T}>\mathrm{CABCB} 11$ polymorphism has shown a similar frequency of homozygote 1331TT genotype $(11.46 \%$ vs. $18.01 \%$ respectively, $O R=0.59, p=0.10)$ and of heterozygote $1331 \mathrm{TC}$ genotype $(48.96 \%$ vs. $52.61 \%$ respectively, $\mathrm{OR}=0.86, \mathrm{p}=0.32$ ). A mutated homozygote $1331 \mathrm{CC}$ genotype was more frequent in the ICP group when compared to the controls ( $39.58 \%$ vs $29.38 \%, O R=1.57, p=0.05$ ).

The frequency of a wild-type $1331 \mathrm{~T}$ allele was higher in the control group ( $35.94 \%$ vs. $44.31 \%, p=0.03$ ), whereas the frequency of a mutated $1331 \mathrm{C}$ allele was higher in the ICP group (64.06\% vs. $55.69 \%, O R=1.42, p=0.03$ ) (Tab. 2).

The analysis of 1954A > G ABCB4 polymorphism has shown that the homozygote 1954AA ABCB4 genotype and the heterozygote 1954AG ABCB4 genotype had similar frequencies across the ICP and the control group (respectively:
$21.88 \%$ vs $17.54 \%, O R=1.32, p=0.23$ and $78.12 \%$ vs $82.46 \%$, $\mathrm{OR}=0.76, \mathrm{p}=0.23$ ). We have not observed the presence of a mutated homozygote 1954GG ABCB4 genotype in neither of the investigated groups. Similar observation applies to alleles' frequency i.e., the presence of both alleles 1954A and $1954 \mathrm{G}$ was similar in both investigated groups (for 1954A allele: 89.06 vs. $91.23 \%, O R=0.78, p=0.24$, for $1954 G$ allele: 10.94 vs. $8.77 \%, O R=1.28, p=0.24)$ (Tab. 3 ).

\section{Analysis of 1331T > C ABCB11 and 1954A > G ABCB4 co-existence}

The cross-tabulation of genotype combinations of $1331 \mathrm{~T}>\mathrm{CABCB} 11$ and 1954A > G ABCB4 is displayed in Table 4. The higher frequency of genotypes containing 2 mutated alleles for $1331 \mathrm{~T}>\mathrm{CABCB} 11$ polymorphism was shown in ICP group then in controls: 1331CC/1954AA (31.25 vs. $25.12, p=0.16)$ and $1331 \mathrm{CC} / 1954 \mathrm{AG}$ (8.33 vs. 4.27, $\mathrm{p}=0.12$ ).

Table 2. The distribution of genotypes and alleles of ABCB11 gene 1331T > C polymorphism among women with ICP and controls

\begin{tabular}{|c|c|c|c|c|c|c|c|}
\hline $\begin{array}{l}A B C B 11 \\
1331 T>C\end{array}$ & \multicolumn{2}{|c|}{$\begin{array}{l}\text { Study group ICP } \\
\qquad(\mathrm{n}=96)\end{array}$} & \multicolumn{2}{|c|}{$\begin{array}{l}\text { Control group } \\
(n=211)\end{array}$} & \multirow{2}{*}{ OR } & \multirow{2}{*}{$95 \% \mathrm{Cl}$} & \multirow{2}{*}{$\mathbf{p}$} \\
\hline Genotypes & $\begin{array}{c}\text { Observed value } \\
n(\%)\end{array}$ & $\begin{array}{c}\text { Expected value } \\
{[\%]}\end{array}$ & $\begin{array}{c}\text { Observed value } \\
\text { n (\%) }\end{array}$ & $\begin{array}{c}\text { Expected value } \\
{[\%]}\end{array}$ & & & \\
\hline TT & $11(11.46)$ & 12.92 & 38 (18.01) & 19.64 & 0.59 & $0.29-1.21$ & 0.10 \\
\hline TC & 47 (48.96) & 46.04 & $111(52.61)$ & 49.35 & 0.86 & $0.53-1.40$ & 0.32 \\
\hline CC & 38 (39.58) & 41.04 & $62(29.38)$ & 31.01 & 1.57 & $0.95-2.61$ & 0.05 \\
\hline Total & $96(100.00)$ & 100.00 & $211(100.00)$ & 100.00 & & & \\
\hline \multicolumn{8}{|l|}{ Alleles } \\
\hline $\mathbf{T}$ & $69(35.94)$ & - & $187(44.31)$ & - & 0.71 & $0.50-1.00$ & 0.03 \\
\hline C & $123(64.06)$ & - & 235 (55.69) & - & 1.42 & $1.00-2.02$ & 0.03 \\
\hline Total & $192(100.00)$ & - & $422(100.00)$ & - & & & \\
\hline
\end{tabular}

HWE: ICP $p=0.54$; CONTROL $p=0.34$

\section{Table 3. The distribution of genotypes and alleles of ABCB4 gene 1954A > G polymorphism among women with ICP and controls}

\begin{tabular}{|c|c|c|c|c|c|c|c|}
\hline $\begin{array}{l}\text { ABCB4 } \\
1954 A>G\end{array}$ & \multicolumn{2}{|c|}{$\begin{array}{l}\text { Study group ICP } \\
\qquad(\mathrm{n}=96)\end{array}$} & \multicolumn{2}{|c|}{$\begin{array}{l}\text { Control group } \\
\quad(n=211)\end{array}$} & \multirow{2}{*}{ OR } & \multirow{2}{*}{$95 \% \mathrm{Cl}$} & \multirow{2}{*}{ p } \\
\hline Genotypes & $\begin{array}{c}\text { Observed value } \\
\text { n (\%) }\end{array}$ & $\begin{array}{c}\text { Expected value } \\
{[\%]}\end{array}$ & $\begin{array}{c}\text { Observed value } \\
\text { n (\%) }\end{array}$ & $\begin{array}{c}\text { Expected value } \\
{[\%]}\end{array}$ & & & \\
\hline$A A$ & 75 (78.12) & 79.32 & $174(82.46)$ & 83.23 & 0.76 & $0.42-1.38$ & 0.23 \\
\hline$A G$ & $21(21.88)$ & 19.48 & 37 (17.54) & 16.00 & 1.32 & $0.72-2.40$ & 0.23 \\
\hline GG & $0(0.00)$ & 1.20 & $0(0.00)$ & 0.77 & - & - & - \\
\hline Total & $96(100.00)$ & 100.00 & $211(100.00)$ & 100.00 & & & \\
\hline \multicolumn{8}{|l|}{ Alleles } \\
\hline A & $171(89.06)$ & - & $385(91.23)$ & - & 0.78 & $0.44-1.38$ & 0.24 \\
\hline $\mathrm{G}$ & $21(10.94)$ & - & 37 (8.77) & - & 1.28 & $0.73-2.25$ & 0.24 \\
\hline Total & $192(100.00)$ & - & $422(100.00)$ & - & & & \\
\hline
\end{tabular}

HWE: ICP $p=0.23 ;$ CONTROL $p=0.16$ 
Table 4. The co-existence rate of the $1331 \mathrm{~T}>C$ and the $1954 \mathrm{~A}>\mathrm{G}$ polymorphisms in the respective $A B C B 11$ and $A B C B 4$ genes of the studied groups

\begin{tabular}{|c|c|c|c|c|c|c|}
\hline & & & \multicolumn{3}{|c|}{ ABCB4 1954A > G } & \multirow[t]{2}{*}{ Total } \\
\hline & & & AA & AG & GG & \\
\hline \multirow{4}{*}{$\begin{array}{l}\text { Study group ICP } \\
(n=96)\end{array}$} & \multirow{4}{*}{$\begin{array}{c}A B C B 11 \\
1331 T>C\end{array}$} & $\mathrm{TT}$ & $9(9.38)$ & $2(2.08)$ & $0(0.00)$ & $11(11.46)$ \\
\hline & & TC & $36(37.5)$ & $11(11.46)$ & $0(0.00)$ & 47 (48.96) \\
\hline & & $\mathrm{CC}$ & $30(31.25)$ & $8(8.33)$ & $0(0.00)$ & 38 (39.58) \\
\hline & & Total & 75 (78.13) & $21(21.88)$ & $0(0.00)$ & $96(100.00)$ \\
\hline \multirow{4}{*}{$\begin{array}{l}\text { Control group } \\
(n=211)\end{array}$} & \multirow{4}{*}{$\begin{array}{c}A B C B 11 \\
1331 T>C\end{array}$} & TT & $29(13.74)$ & $9(4.27)$ & $0(0.00)$ & $38(18.01)$ \\
\hline & & TC & $92(43.60)$ & $19(9.00)$ & $0(0.00)$ & $111(52.61)$ \\
\hline & & CC & $53(25.12)$ & $9(4.27)$ & $0(0.00)$ & 62 (29.38) \\
\hline & & Total & $174(82.46)$ & 37 (17.54) & $0(0.00)$ & $211(100.00)$ \\
\hline
\end{tabular}

\section{DISCUSSION \\ 1331T > C ABCB11 and 1954A > G ABCB4 polymorphisms}

Membrane transporters $A B C B 4$ and $A B C B 11$ are responsible for the removal of the bile acids from hepatocytes. Consequently, their mutated genetic variants may be involved in ICP etiology $[9,19]$. The polymorphism that has received most attention is $1331 \mathrm{~T}>\mathrm{C}$ in the $\mathrm{ABCB} 11$ gene that encodes BSEP.

The role of $1331 \mathrm{~T}>\mathrm{C}$ polymorphism of the $\mathrm{ABCB} 11$ gene has been confirmed in our study. In the group of a total of 96 women with ICP, we have observed a higher frequency of mutated homozygotic genotype 1331 CC (39.58\% vs $29.38 \%$, $\mathrm{OR}=1.57, \mathrm{p}=0.05)$ and a higher frequency of mutated $1331 \mathrm{C}$ allele $(64.06 \%$ vs. $55.69 \%, \mathrm{OR}=1.42, \mathrm{p}=0.03)$ when compared to ICP-free controls.

Other authors have obtained similar results. Meier et al. has shown a probable association between the $1331 \mathrm{~T}>\mathrm{C}$ $A B C B 11$ gene polymorphism and the occurrence of ICP or contraceptive-induced cholestasis $(\mathrm{CIC})$ (4 women with CIC, 41 with ICP, 205 healthy subjects, 40 healthy pregnant women). All women with $\mathrm{CIC}$ were carriers of the mutated 1331C allele. The lowest TBA level was observed in patients with the 1331TT genotype and the highest in patients with the 1331CC genotype. The authors have concluded that a strong dysfunction of bile acid transporters BSEP caused by the presence of $1331 C C A B C B 11$ genotype could lead to the development of cholestasis during oral contraception. It has also been revealed that the presence of $1331 \mathrm{CT}$ $A B C B 11$ genotype could be a reason of developing ICP [9].

Interestingly, women from Asian populations who are known to have a lower incidence of ICP have also been suggested to develop the pathology in association with $A B C B 4$ and $A B C B 11$ gene polymorphisms. Kamimura et al. reports a first Japanese case of a pregnant women with ICP associated with 1331T > C (rs2287622, V444A) ABCB11 and 504C > T (rs1202283, N168N) ABCB4 gene polymorphisms [20].
Many studies focus on a few polymorphisms at once. Wasmuth et al. has analyzed a few polymorphisms of $A B C B 4$ and $A B C B 11$ genes and its haplotypes in Swedish population (e.g. 1331T > C ABCB11 and 1954A > G ABCB4). In a sample of 45,485 pregnant women, 937 reported itching (2.1\%), of which 693 were diagnosed with ICP (TBA $\geq 10 \mu \mathrm{mol} / \mathrm{L})$ (1.5\%) and $130(0.3 \%)$ with a severe ICP (TBA $\geq 40 \mu \mathrm{mol} / \mathrm{L})$. There were no differences as to the frequency of $A B C B 11$ gene haplotypes. Yet, some variants of $A B C B 4$ gene haplotype have shown to be a risk factor for a severe ICP. The ABCB4_5 haplotype in particular was observed more frequently in the study group (5.8\% vs. $0.9 \%$ ) [21].

In our study we have also analyzed a $1954 \mathrm{~A}>\mathrm{G}$ ABCB4 gene polymorphism in the ICP group. We have found no statistically significant difference in the frequency of genotypes and alleles. Similar observations are reported by Bacq et al. who have investigated 8 polymorphisms of $A B C B 4$ gene that is involved in the MDR3 synthesis (50 women with ICP, 107 controls, Caucasian race). No correlation was found between 1954A > G ABCB4 gene polymorphism and the development of ICP. Yet, a statistically significant difference was revealed as to the frequency of Arg590GIn $A B C B 4$ gene polymorphism, which was higher in the ICP group compared to the controls ( $p=0.0017, \mathrm{OR}=16.03$ ) [22].

\section{Coexistence of 1331T > C ABCB11}

\section{and 1954A > G ABCB4 gene polymorphism}

Our study has also performed the analysis of coexistence of polymorphisms in $A B C B 4$ and $A B C B 11$ genes. Higher frequency of coexistence of genotypes containing 2 mutated alleles of 1331T > C ABCB11 polymorphism and 1954A > G variants of $A B C B 4$ gene in ICP group was revealed. These observations are confirmed by other studies. For instance, Dixon et al. have investigated 6 genes involved in the etiology of ICP by analyzing 83 polymorphisms in $A B C B 4$, $A B C B 11, A B C C 2, A T P 8 B 1, N R 1 H 4$ and FGF19 gene. The ICP group consisted of 563 patients whereas the control group 
consisted of 642 healthy pregnant women, all of Caucasian race. The study revealed that the key role in ICP etiology is played by the coexistence of polymorphisms of $A B C B 4$ and ABCB11 genes [19, 23].

Anzivimo et al. arrive to similar conclusions (33 pregnant patients with ICP, Italian population). The authors have revealed 5 new mutations ( 2 in ABCB4 gene: 1587DfsX603, 1738LfsX744 and 3 in ABCB1 1 gene:V284D, Q558H, P731S). The most severe ICP was observed in carriers of I587DfsX603, 1738LfsX744 and V284D mutations [24].

Such strong correlation of various dysfunctional genetic variants involved in the bile acid metabolism confirms the hypothesis that the impairment of bile transport present in ICP can be caused by a dysfunctional genetic variants, especially when in combination. In the course of ICP sudden intrauterine fetal demise may be observed. In turn, in severe ICP the frequency of intrauterine fetal demise is as high as 5.6\% [21, 25-28].

\section{CONCLUSIONS}

Overrepresentation of mutated genetic variants of $1331 \mathrm{~T}>\mathrm{CABCB} 11$ in the ICP group suggests its role in the ICP etiology. The analysis of coexistence of the investigated polymorphisms shows the influence of 1954A > G $A B C B 4$ and $1331 T>C A B C B 11$ on the risk of ICP development. Yet, there is a need to continue genetic studies on larger groups of patients.

\section{REFERENCES}

1. Trauner $M$, Fickert $P$, Wagner M. MDR3 (ABCB4) defects: a paradigm for the genetics of adult cholestatic syndromes. Semin Liver Dis. 2007; 27(1): 77-98, doi: 10.1055/s-2006-960172, indexed in Pubmed: 17295178.

2. Ahmed KT, Almashhrawi AA, Rahman RN, et al. Liver diseases in pregnancy: diseases unique to pregnancy. World J Gastroenterol. 2013; 19(43): 7639-7646, doi: 10.3748/wjg.v19.i43.7639, indexed in Pubmed: 24282353.

3. Lee NM, Brady CW. Liver disease in pregnancy. World J Gastroenterol. 2009; 15(8): 897-906, doi: 10.3748/wjg.15.897, indexed in Pubmed: 19248187.

4. Perez MJ, Briz O. Bile-acid-induced cell injury and protection. World J Gastroenterol. 2009; 15(14): 1677-1689, doi: 10.3748/wjg.15.1677, indexed in Pubmed: 19360911.

5. Kullak-Ublick GA, Beuers U, Paumgartner G. Hepatobiliary transport. J Hepatol. 2000; 32(1 Suppl): 3-18, doi: 10.1016/s0168-8278(00)80411-0, indexed in Pubmed: 10728790.

6. Lang T, Haberl M, Jung D, et al. Genetic variability, haplotype structures, and ethnic diversity of hepatic transporters MDR3 (ABCB4) and bile salt export pump (ABCB11). Drug Metab Dispos. 2006; 34(9): 1582-1599, doi: 10.1124/dmd.105.008854, indexed in Pubmed: 16763017.

7. Arrese $M$, Ananthanarayanan M. The bile salt export pump: molecular properties, function and regulation. Pflugers Arch. 2004; 449(2): 123-131, doi: 10.1007/s00424-004-1311-4, indexed in Pubmed: 15578267.

8. Gotthardt D, Runz H, Keitel V, et al. A mutation in the canalicular phospholipid transporter gene, $A B C B 4$, is associated with cholestasis, ductopenia, and cirrhosis in adults. Hepatology. 2008; 48(4): 1157-1166, doi: 10.1002/hep.22485, indexed in Pubmed: 18781607.

9. Meier $Y$, Zodan $T$, Lang $C$, et al. Increased susceptibility for intrahepatic cholestasis of pregnancy and contraceptive-induced cholestasis in carriers of the $1331 \mathrm{~T}>\mathrm{C}$ polymorphism in the bile salt export pump. World J Gastroenterol. 2008; 14(1): 38-45, doi: http://dx.doi. org/10.3748/wjg.14.38, indexed in Pubmed: 18176959.

10. Jacquemin E, Cresteil D, Manouvrier S, et al. Heterozygous non-sense mutation of the MDR3 gene in familial intrahepatic cholestasis of pregnancy. Lancet. 1999; 353(9148): 210-211, doi: 10.1016/S0140-6736(05)77221-4, indexed in Pubmed: 9923886.

11. Dixon PH, Weerasekera N, Linton KJ, et al. Heterozygous MDR3 missense mutation associated with intrahepatic cholestasis of pregnancy: evidence for a defect in protein trafficking. Hum Mol Genet. 2000; 9(8): 1209-1217, doi: 10.1093/hmg/9.8.1209, indexed in Pubmed: 10767346.

12. Alrefai WA, Gill RK. Bile acid transporters: structure, function, regulation and pathophysiological implications. Pharm Res. 2007; 24(10): 1803-1823, doi: 10.1007/s1 1095-007-9289-1, indexed in Pubmed: 17404808.

13. Kufelnicka-Babout M, Smolarz B, Kulig A, et al. Znaczenie polimorfizmu T129C i G2677T genu MDR1 u pacjentek z rakiem jajnika. Prz Menopauz. 2008; 6: 295-300.

14. Lefebvre $P$, Cariou B, Lien F, et al. Role of bile acids and bile acid receptors in metabolic regulation. Physiol Rev. 2009; 89(1): 147-191, doi: 10.1152/physrev.00010.2008, indexed in Pubmed: 19126757.

15. Thompson R, Strautnieks S. BSEP: function and role in progressive familial intrahepatic cholestasis. Semin Liver Dis. 2001; 21(4): 545-550, doi: 10.1055/s-2001-19038, indexed in Pubmed: 11745042.

16. Jacquemin $E$. Role of multidrug resistance 3 deficiency in pediatric and adult liver disease: one gene for three diseases. Semin Liver Dis. 2001; 21(4): 551-562, doi: 10.1055/s-2001-19033, indexed in Pubmed: 11745043.

17. Dias VLM. Nuclear receptor signaling pathways in cardiovascular disease. Expression profile and pharmacogenetics of genes candidate to play a role in cardiovascular disease. Universidade do Algarve. ; 2010: 1-199.

18. Bronský J, Jirsa M, Nevoral J, et al. Role of common canalicular transporter gene variations in aetiology of idiopathic gallstones in childhood. Folia Biol (Praha). 2010; 56(1): 9-13, indexed in Pubmed: 20163776.

19. Dixon $\mathrm{PH}$, Wadsworth $\mathrm{CA}, \mathrm{Chambers} \mathrm{J,} \mathrm{et} \mathrm{al.} \mathrm{A} \mathrm{comprehensive} \mathrm{analysis}$ of common genetic variation around six candidate loci for intrahepatic cholestasis of pregnancy. Am J Gastroenterol. 2014; 109(1): 76-84, doi: 10.1038/ajg.2013.406, indexed in Pubmed: 24366234.

20. Kamimura $\mathrm{K}$, Abe $\mathrm{H}$, Kamimura $\mathrm{N}$, et al. Successful management of severe intrahepatic cholestasis of pregnancy: report of a first Japanese case. BMC Gastroenterol. 2014; 14: 160, doi: 10.1186/1471-230X-14-160, indexed in Pubmed: 25218883.

21. Wasmuth HE, Glantz A, Keppeler H, et al. Intrahepatic cholestasis of pregnancy: the severe form is associated with common variants of the hepatobiliary phospholipid transporter ABCB4 gene. Gut. 2007; 56(2): 265-270, doi: 10.1136/gut.2006.092742, indexed in Pubmed: 16891356.

22. Bacq Y, Gendrot $C$, Perrotin F, et al. ABCB4 gene mutations and single-nucleotide polymorphisms in women with intrahepatic cholestasis of pregnancy. J Med Genet. 2009; 46(10): 711-715, doi: 10.1136/jmg.2009.067397, indexed in Pubmed: 19584064.

23. Chappell S, Morgan L. Searching for genetic clues to the causes of pre-eclampsia. Clin Sci (Lond). 2006; 110(4):443-458, doi: 10.1042/CS20050323, indexed in Pubmed: 16526948.

24. Anzivino $C$, Odoardi MR, Meschiari E, et al. ABCB4 and ABCB11 mutations in intrahepatic cholestasis of pregnancy in an Italian population. Dig Liver Dis. 2013; 45(3): 226-232, doi: 10.1016/j.dld.2012.08.011, indexed in Pubmed: 23022423.

25. Glantz A, Marschall HU, Mattsson LA. Intrahepatic cholestasis of pregnancy: Relationships between bile acid levels and fetal complication rates. Hepatology. 2004; 40(2): 467-474, doi: 10.1002/hep.20336, indexed in Pubmed: 15368452.

26. Mirfazeli A, Sedehi M, Golalipour MJ. Neonatal and prenatal causes of death in Gorgan-North of Iran. Med J Islam Repub Iran. 2014; 28: 43, indexed in Pubmed: 25405109.

27. Silver RM, Saade GR, Thorsten V, et al. Factor V Leiden, prothrombin G20210A, and methylene tetrahydrofolate reductase mutations and stillbirth: the Stillbirth Collaborative Research Network. Am J Obstet Gynecol. 2016; 215(4):468.e1-468.e17, doi: 10.1016/j.ajog.2016.04.026, indexed in Pubmed: 27131585.

28. Drews K, Różycka A, Barlik M, et al. Polymorphic variants of genes involved in choline pathway and the risk of intrauterine fetal death. Ginekol Pol. 2017; 88(4): 205-211, doi: 10.5603/GP.a2017.0039, indexed in Pubmed: 28509322 